\title{
Teaching Translation Studies at the University of Western Australia and Relevant Implications Observed*
}

\author{
TANG Wen-li \\ Guangdong Polytechnic Normal University, Guangzhou, China
}

\begin{abstract}
This paper introduces the second semester teaching of the two-year course (Master of Translation Studies) in the University of Western Australia (UWA). The author gives a detailed review of four translation units, those being the ones related to just the Chinese and English two way parts that she attended. The author's comments and students' feedback are included. Three main questions are answered in this article. They are: What are the popular translation teaching methods to achieve the learning outcomes? What are the implications for how to minimize the use of Chinglish $^{1}$ (Chinese English) in Chinese-English translation? And also, what translation teaching methods used at UWA can be adopted in the Chinese College English classroom to better develop non-English-majored college students' translation competence? The paper concludes by summarizing that to minimize the use of Chinglish and improve translation competence, developing the skills of reading, writing, listening, and speaking is indispensable.
\end{abstract}

Keywords: translation teaching, College English translation teaching, translation teaching method, translation competence, Chinglish

\section{Introduction}

The form of translation session in College English Test (CET): CET is a national English as a foreign language test in China to assess the English proficiency of non-English-majored college students. In order to further emphasize the importance of college students' competence in English language application, the National College English Test Committee has changed the form of Translation Session from "Complete the sentences by translating into English the Chinese given in brackets" into "Translate a passage from Chinese into English", whose contents range from Chinese culture and history, economy, to society. This adjustment poses a great

\footnotetext{
* Acknowledgements: The author is grateful to the comments and suggestions of Professor Helene Jaccomard, from Faculty of Arts, the University of Western Australia at the initial stage of this paper. The author is much obliged to Mr. Jesse Jacobs for his revision and proof-reading of the paper. The author also extends her thanks to all the participants of this study for their cooperation. Special gratitude shall go to all the reviewers and editors for their valuable and helpful comments on the revision of this paper. Lastly the author would like to give her heartfelt thanks to Guangdong Polytechnic Normal University that funded her research in the University of Western Australia.

TANG Wen-li, professor, master, College English Department, Guangdong Polytechnic Normal University.

${ }^{1}$ Chinglish refers to spoken or written English language that is influenced by the Chinese language. The term "Chinglish" is commonly applied to ungrammatical or nonsensical English in Chinese contexts, and may have pejorative or deprecating connotations. See http://en.wikipedia.org/wiki/Chinglish.
} 
challenge for students' translation competence. It is also necessary for College English teachers ${ }^{2}$ to reflect on their teaching contents and methods and seek ways to improve students' translation competence so that students' English expressions become more accurate and idiomatic.

\section{Literature Review}

\section{Translation Teaching Methods}

In some universities of China with Translation Major, teaching methods like students' self-reflection, interaction, and team-based teaching are common and proved effective to improve students' translation competence (LIU, 2011). Unfortunately, according to LIU He-ping (2013), many teachers still teach translation as they used to teach "Intensive Reading", using Grammar-Translation method to analyze each sentence in the classroom. In China, the most popular translation teaching procedure in training English majors is still lecture, after class exercises, and teacher's comments in class (very often includes giving "correct" answer and analyzing difficult sentences) (YANG, 2002). To a great degree, this teaching procedure means that translation learning has been confused with language learning, which varies considerably from professional translation teaching. As a result, the quality of translation teaching is hard to be guaranteed. It is suggested that task-based teaching (TBT), an approach that shifts the focus onto the students, should be adopted in business translator training (LI, 2013). Gile (2004) presents a systematic retrospection method in his article on Integrated Problem and Decision Reporting as a Translator Training Tool. This method requires "students describe their translation problems and the strategies they used to solve them, what sources and aids they have consulted and what decisions they have taken" (Gile, 2004, p. 2). The purpose of it is to find out the causes of problems and errors in translation products. Similar methods are tested and compared in Hansen (2006)'s Copenhagen Retrospection Project, such as "Retrospection with Replay with Translog $(\mathrm{R}+\mathrm{Rp})$ and Retrospection with Replay combined with cognitive clarification via an immediate dialogue (ID) between the subject and the observer ( $\mathrm{R}+\mathrm{Rp}+\mathrm{ID}$ )". The result is that each method or the combination of the methods in his project has its advantages and is suited to be used in translation teaching and research. In some translators' training program, trainees are asked to write down the translators' notes, with the purpose of developing a concept of pre-translation research, a "due process" for quality translation (LI, 2006).

\section{The Present Situation of Translation Teaching in Chinese College English Classroom}

The major part of the present College English teaching is the Integrated Course studies, which include listening, speaking, intensive reading, writing, and translating in general. Each unit of the Integrated Course contains Chinese and English in both direction with sentences' and passages' translation exercises. In the College English classroom, translation theories are rarely talked about. Some teachers usually spend 20 minutes at most to talk about some specific translation skills relating to the translation exercises in each unit. Normally, a teacher will ask a student to translate a sentence orally then point out the errors in it and give the "correct" answer to it. Other students may take notes while the teacher talks.

The dominant translation teaching method currently used in the modern Chinese College English classroom is textbook-based and teacher-centered. As most students usually do not do the translation exercises, there are no

\footnotetext{
${ }^{2}$ College English teachers refer to those who teach English to non-English-majored college students.
} 
or few teacher-students and students-students interactions in translation teaching. In fact, not many teachers are willing to use the method of teacher-students interaction because once they use it, they will face various translations from students and some of which risk being beyond their expertise to clarify. After all, College English teachers are not English native speakers and their translation competence can be at times less than ideal. Consequently, to avoid the risk of their authority as a teacher being challenged in front of all the class to see and the associated possible embarrassment and loss of face, most teachers choose the teacher-centered translation teaching method. On the other hand, due to lack of practice and accurate correction, students' translation competence is far from satisfactory. Errors such as "wrong choice of word", "expression ambiguity", "wrong sentence structure", and "wrong expression" are thus very common in students' passage translation exercises. In this difficult situation, both College English teachers and students get frustrated as to how to effectively improve their translation competence.

Based on the above translation teaching methods for professional translators and the current situation of College English translation teaching in China, I would like to take the opportunity as a visiting academic to the University of Western Australia to explore the following problems in translation teaching. As few literature both at home and abroad in recent years has focused on non-English-majored college students' translation competence, which is essential in communication, I hope my experience of attending the four translation units will eventually help improve non-English majors' translation competence as well as my own English teaching technique. The following parts are the introduction of the UWA four translation units, students' feedback on them, and the author as an observer's comments.

\section{Research Questions}

What are the popular translation teaching methods for students of "Master of Translation Studies" in the UWA to achieve the learning outcomes?

What are the implications for how to minimize Chinglish in Chinese-English translation?

What translation teaching methods of the UWA can be adopted in Chinese College English classroom to better develop students' translation competence?

\section{Methods}

\section{Subject}

As there were only seven students enrolled in the degree of Master of Translation Studies, with five doing the Chinese/English stream (the other two students did French and Italian respectively). I chose three of them to be surveyed because their questionnaires were valid. They were all female and their average age was 25 . Their undergraduate majors were all different and they were from three different cities in China.

Since there were only three students selected in the study, it was difficult for the author to generalize the findings about the students' experience. The data collected from the questionnaire will thus only be used to support the descriptive analysis. The author's observations objectively try to compensate to some extent for the lack of available student subjects.

\section{Procedures}

The methods of this research are class observation, questionnaire, and interview. The "observer's comment" 
in this article was based on the notes of the author's class observation, the questionnaire, and the interview. The questionnaire consists of two sessions. The first session (see Appendix) contains 11 statements with 7-point scale, namely, $1=$ strongly disagree, $2=$ moderately disagree, $3=$ slightly disagree, $4=$ neutral, $5=$ slightly agree, $6=$ moderately agree, and $7=$ strongly agree. The number of each choice represents the score of each statement. To minimize extreme response bias and acquiescent bias (namely in case students provide all high or all low ratings), statement 8,9,10, and 11 are the negative statements of 1,2,3, and 4 . The scores of these statements were given in reversed order. The higher score a statement got, the more a student agreed on the statement. The lower score a negative statement got, the less a student agreed on the statement. The students were required to mark their choices that applied to each study unit.

The second session was short-answer questions. The interview questions were from the second session of the questionnaire in case students had more to say and minutes were kept.

\section{Results}

\section{Learning Management System (LMS)}

Before the introduction of the four units, it is necessary to introduce LMS. LMS is a learning management system of the UWA. Students need to log into LMS almost everyday to check important announcements, pre-reading materials, homework, and the like. In LMS, each lecturer is required to post all the details of his/her course. The details included but not limited to the below: ${ }^{3}$

(1) Unit details (unit title, unit code, availability, and location);

(2) Contact details (lecturers' office telephone, email, and office consultation hours);

(3) Unit description (objectives, learning outcomes, unit structure, and unit schedule);

(4) Teaching and learning responsibilities (teaching and learning strategies, charter of student rights and responsibilities, student guild contact details);

(5) Academic conduct essentials;

(6) Assessment overview (assessment mechanism, assessment items, academic literacy, and academic misconduct, such as plagiarism and appeals against academic assessment);

(7) Textbooks and resources (recommended books, texts, and reading materials).

\section{Unit Introduction, Observer's Comment, and Students' Feedback}

"Master of Translation Studies of the UWA is a two-year full time course or five-year (Maximum) part time course". The author observed classes of four units in the second semester of year one. The characteristics of each unit are as follows:

\section{Unit 1: Interdisciplinary translation studies.}

Objectives. "This unit introduces students to Translation Studies by exploring the history of translation from China to Europe, bringing to light major translators, practitioners and thinkers alike. Along the way, key concepts such as equivalence and equivalent effect, translation style, and translation universals are shown to underpin the theoretical debates and disciplinary development of translation studies in the past as well as in contemporary times".

\footnotetext{
3 Resources are from the Unit Outline of Interdisciplinary Translation, TRNS5002, SEM-2, 2014, by Helene Jaccomard.

${ }^{4}$ See http://www.studyat.uwa.edu.au/courses/master-of-translation-studies-coursework\#Description.

5 Quoted in the brochure of "Master of Translation Studies", Faculty of Arts, the University of Western Australia, UniPrint 115087.
} 
Learning outcomes. "Students (1) acquire a systematic and thorough understanding of the historical making of important modern and contemporary translation theories; (2) develop critical and independent thinking regarding the strength and limitation of distinct translation schools; and (3) learn to apply the theoretical knowledge in the study of specific translation phenomena and events identified in real-life contexts". 6

Teaching method: Lectures/tutorials. Teaching methods of Unit 1 are discussed.

Teaching steps. This teaching method mainly was in the form of lectures and tutorials, namely a 45 -minute lecture and a 45-minute tutorial. The lecture part was teacher-centered teaching. There was no textbook for this unit. However, students were required to read articles and think about the relating questions in advance to familiarize themselves with the contents of a lecture. The reading materials and the power point presentation of a lecture were posted on LMS before the lecture. The second part of the lesson was the time for students-students and teacher-students interaction based on the questions on the lecture and the relating weekly readings. Weekly or biweekly homework was a 500-word essay. It would be submitted via LMS before the deadline.

Students' feedback (Unit 1). Table 1 shows the sum of scores student 1, student 2, and student 3 got in statement 1 and 8 are 4, 3, and 12 respectively (St1: $2+2=4$, St2: $2+1=3$, St3: $6+6=12$; In Statement 1, Student 1 chose " 2 = moderately disagree" and got 2 scores. In the corresponding negative Statement 8 , Student 1 chose " 6 = moderately agree" and also got 2 scores according to the rule of negative statements' scores being given in reversed order, and so on). This illustrates that $\mathrm{S} 1$ and $\mathrm{S} 2$, to a large extent, did not think the unit could effectively improve their translation competence. According to the interview and their answers in session 2 of the questionnaire, St1 and St2 thought even though the theories were abstract, they learned some translation theories but could not see how the theories benefited their translation competence. However, S3 got much higher score (12), which explains her opposite opinion. She claimed she had a deeper understanding of translation theories and concepts especially after reading the pre-reading materials with worksheets before class. She suggested more pre-reading materials with easy-to-understand worksheet might be more helpful to students. Table 1 also displays all the three students agreed this unit could, to some degree, improve their ability of reading, writing, listening, and speaking. In statement 4, St2 and St3 moderately/strongly agreed that this unit could develop the ability of independent and critical thinking.

Table 1

Students' Feedback on Unit 1

\begin{tabular}{lllll}
\hline Statement & $\mathrm{St1}^{\mathrm{a}}$ & $\mathrm{St} 2$ & $\mathrm{St3}$ & Subtotal \\
\hline S1/S8: This unit can/cannot effectively improve my translation competence. & $2^{\mathrm{b}} / 2^{\mathrm{c}}$ & $2 / 1$ & $6 / 6$ & 19 \\
S2/S9: This unit can/cannot effectively improve my ability of reading, writing, & $4 / 6$ & $4 / 4$ & $5 / 7$ & 30 \\
listening, and speaking. & & & 25 \\
S3/S10: This unit can/cannot help to achieve the goal of cultivating Master of & $3 / 6$ & $2 / 1$ & $6 / 7$ & 25 \\
$\begin{array}{l}\text { Translation. } \\
\text { S4/S11: This unit can/cannot foster teaching contents and develop the ability of } \\
\text { independent and critical thinking. }\end{array}$ & $3 / 6$ & $6 / 3$ & $7 / 7$ & 32 \\
\hline Total & & & & 106 \\
\hline
\end{tabular}

Note. ${ }^{\text {a, b, c }}$ student 1 got 2 scores in statement 1 and got 2 scores in statement 8.

${ }^{6}$ Quoted in the Unit Outline of Interdisciplinary Translation, TRNS5002, SEM-2, 2014, by Helene Jaccomard. 
Observer's comment. This was a non-language specific unit, where students from different language pairs were taught together. It was divided into five sessions, each of which was given by a different lecturer. All the five lecturers are professional translators or interpreters with the relevant experience. They have translated and published quite a lot of papers in their own research field. Besides this subject relevant experience, their qualifications have been approved by the NAATI (National Accreditation Authority for Translators and Interpreters of Australia). Professor Helene Jaccomard is the coordinator of Unit 1. She is a Professor of French Studies with rich experience in translation and interpretation as well as translation theories and has published articles on literary and drama translation. In the first lecture, Professor Jaccomard elaborated, "Why translation studies are interdisciplinary" and the three main approaches (textual, socio-cultural, and philosophical) to translation studies. The second lecture was presented by Anna Gadd Colombi, who has just completed her Ph.D. on the translation of Jolley's Mr. Scobie's Riddle. In Anna's first lecture, she hoped the students "comprehend that texts do not stand alone, but rather they are part of a culture and they represent a language". Anna also introduced Gideon Toury's notions of textemes and repertoremes and their treatment in literary translation. Associate Professor Meng Ji mainly focused on Corpus Methods for Descriptive Translation Studies. Assistant Professor Shalmalee Palekar focused her topic on the issue of translation and its place in contemporary literature in postcolonial studies. Assistant Professor Dale Adams introduced the philosophy of translation and the relationship of translation to political ideology.

Although this unit belonged to translation theories learning, it was taught half of the time in an interactive way. Students could learn not only different schools of translation technique and concepts but also languages and cultures even though some theories were seemingly abstract to them. Students were impressed by Assistant Professor Dale Adams's worksheets (a reading comprehension exercise to help students understand the key points in an article) because they expressed that they had more confidence in class after they have completed a worksheet beforehand. In addition, students were able to access LMS and teachers' lecture if they needed to review a particular area of instruction. If a student wanted to understand the key concepts in the pre-reading materials, he or she needed to better prepare him or herself before attending class. Otherwise, the student risked being embarrassed during discussion because of their inability to constructively contribute to the class. The essential part of the unit was the essay writing after each module. Students needed to fully digest the contents of the lecture before they could generate their own opinions on a certain issue. During this process student's independent and critical thinking skills were developed.

The translation theories taught in Unit 1 were mainly concerned with macro problems in translation rather than micro problems like how to translate a certain sentence. Students who could not see how the theories benefited their translation competence may here have ignored a basic truth. That is - translation studies should be the combination of micro study of language and macro study of politics, economy, culture, and history. Given the fact that two other part-time students were doing the course in another pair of languages rather than English/Chinese, it was unrealistic for lecturers to talk about translation skills in class specific just to one language set.

\section{Unit 2: Advanced language skill/culture and media.}

Objectives. "This unit aims to help students develop advanced reading, writing, listening and speaking skills in the target language. It is delivered by means of multimedia tools such as video recording and online materials. 
Listening comprehension materials are furnished in class to cover a variety of textual genres such as news reporting, mass media, IT and technology, economic and commercial materials, and so on. Intensive in-class exercises are combined with explanations of relevant social and cultural backgrounds to enable students to gain insights into the target language system under study".7

Learning outcomes. "Students (1) acquire advanced listening and speaking skills in the target language, i.e., Mandarin Chinese for English-speaking students and English for Chinese students; (2) develop reading and writing skills in the target language; (3) develop effective practical communication skills in a variety of real-life contexts and make useful preparations for future careers in diverse settings; and (4) gain a thorough understanding of relevant social and cultural phenomena in the target language and cultural context". 8

"In addition, students should be able to (1) read, understand and digest texts under limited time conditions; (2) put forward convincing arguments both orally in class and in written form in a succinct and measured way; (3) convert important parts of the text from English into Chinese; (4) show an understanding of texts through comprehension and be able to put forward substantiated opinions on a particular text; and (5) locate and bring to class articles that the student is interested in to share with the class" (ibid.).

Teaching method: Interaction-Reflection-Internalization in tutorials. Teaching methods of Unit 2 are discussed.

Teaching steps. This teaching method was a combination of interaction, reflection, and internalization in tutorials. I would like to illustrate this method with a lesson with the topic of "Contemporary Australian Culture". Students were required to prepare well for the topic discussion by visiting a designated website (Contemporary Australian Culture) and selecting one of the 13 part series to listen to and read. Each student was expected to select a different sub-topic to write his/her journal entry and submit it in the next class.

The teaching steps were clearly set up. First, the lecturer returned students' journal entries (about 500 words, assigned in the previous week) and made comments on the common mistakes in them such as format, structure, how to write a concise opening paragraph and a conclusion providing much food for thought. The second step was for students to clarify on areas of the pre-reading that they did not fully understand or comprehend. Then the topic of "Contemporary Australian Culture" served as a starting point for student-teacher discussion in the form of Q \& A session (question and answer). At this point each student was asked often in random order to briefly summarize his/her journal entry and thoughts and share these with the class. The lecturer asked various questions based on their different sub-topics, such as Australian people, culture, politics, education, suburbia, sports, jobs, and etc.

Students' feedback (Unit 2). According to the collected "Mid term feedback" (prepared by the lecturer, Mr. Jesse Jacobs) from the students and the informal interview with them, all the 16 students' feedback was extremely positive (11 students enrolled in the Business School's Master of Commerce take this unit as an elective. The other five students are enrolled in the translation Masters program). Good comments on the course ranged from "hot and interesting topics for discussion", "happy learning experience", "helped improve my language ability and exposed me to rich and varied Australian culture..." to "The lecturer creates a easy-going learning atmosphere where learning outcomes are still fruitful".

\footnotetext{
7 Quoted in the brochure of "Master of Translation Studies", Faculty of Arts, the University of Western Australia, UniPrint 115087.

${ }^{8}$ Quoted in the Unit Outline of Advanced Language 2, SEM-2, 2014, by Jesse Jabobs.
} 
Table 2 displays the scores the three students got in statement 1 and 8, 2 and 9, 3 and 10, 4 and 11. Most scores are 5,6, and 7, which means this unit may better embody the descriptions of statement 1,2,3, and 4. Most importantly, according to their written feedback in the questionnaire designed by the author, three students stressed the wide variety of reading of text genres and the journal writings broadened their horizon, expanded their cross-cultural awareness, and improved their ability of critical thinking. All these combined to lay the foundation for their future translation jobs. Meanwhile, the three students expressed the desire for more insightful classroom discussions.

Table 2

Students' Feedback on Unit 2

\begin{tabular}{lllll}
\hline Statement & St1 & St2 & St3 & Subtotal \\
\hline S1/S8: This unit can/cannot effectively improve my translation competence. & $6 / 7$ & $5 / 3$ & $6 / 6$ & 33 \\
S2/S9: This unit can/cannot effectively improve my ability of reading, writing, & $6 / 6$ & $5 / 6$ & $7 / 7$ & 37 \\
listening, and speaking. & & & & 30 \\
S3/S10: This unit can/cannot help to achieve the goal of cultivating Master of & $6 / 6$ & $4 / 3$ & $5 / 6$ & 30 \\
Translation. & $6 / 6$ & $4 / 7$ & $7 / 7$ & 37 \\
$\begin{array}{l}\text { S4/S11: This unit can/cannot foster teaching contents and develop the ability of } \\
\text { independent and critical thinking. }\end{array}$ & & & & 137 \\
\hline Total & & & \\
\hline
\end{tabular}

Observer's comment. The lecturer of this unit is Mr. Jesse Jacobs. Mr. Jacobs got his bachelor and master's degree in Peking University of China. He is a NAATI accredited professional Simultaneous Interpreter (Level 3, Chinese and English). One of the characteristics of Mr. Jacobs' class was his witty and intuitive questions for the students. He raised his questions one after another just like the bursts of bullets fired from a gun. This prevented the students from not having any chance of being absent-minded at all as at anytime a student may be asked to reply to a question. In fact, the precondition of using interactive teaching method was to cultivate the awareness of "questions". This was a big challenge both for a teacher and a student. It took the teacher much more time to select interesting topics most students are familiar with, which helped students actively put forward to their questions or opinions in class. In addition to this, the teacher must first foresee or perceive the difficult or confusing questions students might come across in the lessons before he carefully designed questions for students to students and teacher to students interactions. On the other hand, a student must also fully prepare for the lessons orally or in written form before they came to classes. Otherwise his/her silence or lack of insight by giving a short and ill thought out answer in interactions would directly impact their academic performance as $15 \%$ of the classes mark was made up by in class discussion from students. To give effective guidance to classroom discussions, Mr. Jacobs mainly adopted the method of teacher-students interaction. This was possible mainly due to the small class size and seating arrangement of the students being all sitting around a large table. In the process of asking, answering, clarifying, and reflecting on all the questions, students' thoughts and perceptions of a topic broadened, deepened, and were internalized while at the same time improving the students language skills.

\section{Unit 3: Translation localization.}

Objectives. "Localization represents a rapidly growing knowledge-based industry in a globalized world. The main purpose of this unit is to introduce the latest localization software and encourage students to have 
practical hands-on experience to effect the localization of texts for specific markets operating in a growing globalization". 9

Learning outcome. "Students (1) develop knowledge and practical use of computer-assisted translation (CAT) tools, e.g., SDL Multi-Term Extract; (2) develop practical skills of the use of latest computer-assisted translation technology, e.g., SDL Studio 2014; and (3) develop individual and team translation skills by simulating real workplace environment". ${ }^{10}$

Teaching method. Lectures in computer laboratory — teacher's demonstrations—students' hands-on practice - simulation of real workplace.

Teaching steps. Each class of this unit lasted 1.5 hours. The lecturer demonstrated how to use translation software in the computer lab via power point presentation. Students followed step by step on their own computers. During the process, the lecturer walked around and made sure each student was on task and keeping up with the instruction. After class, students were supposed to be able to repeat the steps alone. The two simulated translation projects for the students best demonstrated the characteristic of this course. The first one which was to construct a term base in the computer should be finished independently and the second one was a team project. The detail requirements are as follows. ${ }^{11}$

(1) Construct a term base: Requirement: Each student is asked to develop a term base of English and his/her target language by using SDL Multiterm Extract. The term base should contain a minimum of 50 term pairs in a specialized field, e.g., science, medicine, engineering, law, economics/finance.

Assessment criteria contain two parts, namely, a constructed term base and a report of a self-reflective assessment during the construction of the term base.

(2) Team project: Requirement: Five students are asked to form a translation team (two students as translators, two students as terminologists and quality assurance officers, and one student as project manager).

As a team, students are asked to translate a 2000-word document which is highly specialized. To ensure the quality and efficiency of translation, students need to leverage human resources and translation technology by: (a) effective teamwork and translation workflow management; (b) creation of high quality MT resources: e.g., TM; term-bases, etc., to ensure terminology consistency; and (c) high quality translation delivered within the tight framework given.

Assessment criteria for translators/terminologists:

(1) Teamwork (30\%) (based on a peer assessment questionnaire);

(2) Overall quality of the translation (20\%);

(3) Individual report (50\%) (demonstrate how well/efficient one uses CAT tools) (300 words).

Assessment criteria for project manager's report:

(1) Work plan and task assignment: a clearly defined work plan which sets out a feasible progress schedule to leverage the work force and resources available --> who does what at which stage;

(2) Process monitoring: identification of problems and development of problem-solving strategies;

\footnotetext{
${ }^{9}$ Quoted in the brochure of "Master of Translation Studies", Faculty of Arts, the University of Western Australia, UniPrint 115087.

${ }^{10}$ Quoted in the Unit Outline of Translation Localisation, SEM-2, 2014, by Ji Meng.

11 Quoted in the Unit Outline of Translation Localisation, lesson layout in the Learning Management System (LMS), SEM-2, 2014, by Ji Meng.
} 
(3) Project summary and statistics report;

(4) Assessment of individual performance and teamwork.

Team formation process and workflow:

Week 1-2: Get to know each other and identify a translation field of common interest: scientific, technology, environment, medicine, business, etc.

Week 3-5: Data collection and construction of a subject-specific translation term base.

Week 6-7: Start to design a translation project "title" and design a simulated translation scenario.

Week 8-9: Discussion and refinement of the translation project design; the project manager is to finalise a viable work plan (see instructions under Assignment).

Study break:

Week 10-12: Team translation work (regular meetings and discussion).

Week 13: Submission of the translation project (allocated individual translation; peer assessment form; individual report and the manager's report).

Students' Feedback (Unit 3). According to the short-answer question of the author's questionnaire, all the three students agreed that the unit was very practical and gave them a good command of SDL (a popular translation software), which effectively improved their translation efficiency. The simulated term base construction and team project can make the students familiar with the different roles in authentic translation workshops. In Table 3, statement 1/8, 3/10, and 4/11 also illustrate the same result.

Table 3

Students' Feedback on Unit 3

\begin{tabular}{|c|c|c|c|c|}
\hline Statement & St1 & St2 & St3 & Subtotal \\
\hline S1/S8: This unit can/cannot effectively improve my translation competence. & $6 / 7$ & $5 / 2$ & $7 / 7$ & 34 \\
\hline $\begin{array}{l}\text { S2/S9: This unit can/cannot effectively improve my ability of reading, writing, } \\
\text { listening, and speaking. }\end{array}$ & $6 / 6$ & $4 / 2$ & $4 / 6$ & 28 \\
\hline $\begin{array}{l}\text { S3/S10: This unit can/cannot help to achieve the goal of cultivating Master of } \\
\text { Translation. }\end{array}$ & $6 / 6$ & $3 / 4$ & $5 / 7$ & 31 \\
\hline $\begin{array}{l}\text { S4/S11: This unit can/cannot foster teaching contents and develop the ability of } \\
\text { independent and critical thinking. }\end{array}$ & $6 / 6$ & $7 / 7$ & $6 / 7$ & 39 \\
\hline Total & & & & 132 \\
\hline
\end{tabular}

Observer's comment. Like Unit 1, this was also a non-language specific unit, where students from different language pairs were taught together. This unit was taught by Associate Professor Meng Ji. Her teaching and research mainly covered corpus translation studies, translation technology, translation research methodologies, literary translation, stylistics, translation, and digital media. The teaching method of this unit was characterized by hands-on practice and team project assignment in terms of authentic professional translation procedures. Since fitting authentic translation projects into a scheduled unit learning proved insurmountable for some teachers, simulated translation projects may be the best alternative (LI, 2013), because simulation "has come to be widely recognized as a valuable means of learning about a whole range of phenomena" (Crookall \& Oxford, 1990, p. 14). Besides, "the most critical point in cultivating applied talent is hands-on practice" (LIU, 2013, p. 54). If the teacher's teaching and students' learning are based on real or simulated tasks, students' overall translation competence can be developed through task assignment, task design, work-plan, implementation, and self/peer 
assessment. Simultaneously, students can be gradually exposed to a real workplace environment in hands-on practice. It is in the process of understanding, summarizing, and internalizing what they have learned that their translation and problem-solving abilities improve. In addition to this, students' awareness of involvement and responsibility will be strengthened by the team project assignment, in which each role has been explicitly described. Another essential part of the team project assignment is the explicit and detailed assessment criteria for each role. I believe that after the completion of this unit, students benefited not only from the experience of using the most sophisticated translation software but also from the lecturer's rigorous teaching attitude.

One point needs paying attention to is that Table 3 shows statement $2 / 9$ got relatively low subtotal score (28) compared with that of Unit 1 (30), Unit 2 (37), and Unit 4 (37). The objective reason was that Unit 3 was designed to "develop practical skills of the use of latest computer-assisted translation technology" rather than improving students' ability of reading, writing, listening, and speaking. It emphasizes students' hands-on experience.

\section{Unit 4: General/specialized translation.}

Objectives. "The main purpose of this unit is to provide practical training to students for their future career as professional translators. This unit aims to further develop students' advanced language skills in English and the target language, as well as cultural knowledge. The text types examined may be literary texts, multi-media texts, and subtitles". ${ }^{12}$

Learning outcome. By the regular and intense translating practice, students will build awareness on fundamental translation techniques.

Teaching method: Practice-Interaction-Clarification. This unit was divided into two parts. Each part lasted for six weeks. One was English-Chinese translation taught by Associate Professor Meng Ji, whose native language is Chinese. The other is Chinese-English translation by Associate Professor Andrew, an Australian teacher whose native language is English. The teaching steps of them are as follows:

Teaching steps of English-Chinese translation. (1) Each student translated an article of about 1,000 words from English into Chinese and submitted it on LMS by each Friday;

(2) The teacher marked good sentences, sentences that needed substantial changes and minor changes by using three different colors. The assignment feedback would be sent to students before the next class;

(3) Teacher-student discussion in class was focused on difficult words and phrases, controversial, or long sentences with complicated structure;

(4) During the last 30 minutes of a class, there would be targeted translation practice on non-attributive clauses, appositive clauses, long sentences, voice conversion, word addition, etc. Pair discussion and teacher-student interaction were often used in this part of the class;

(5) The keys to all exercises would be posted on LMS for students' reference after class.

Students' feedback (Unit 4). English-Chinese: The three students expressed the same feelings that when doing English-Chinese translation, the most difficult parts of English-Chinese translation were the understanding of English text and deficiencies of Chinese language vocabulary. "Sometimes I understand the meaning of the source text, but I just cannot find an appropriate Chinese expression, I think I really need to enlarge my Chinese

${ }^{12}$ Quoted in the brochure of "Master of Translation Studies", Faculty of Arts, the University of Western Australia, UniPrint 115087. 
vocabulary as well as English vocabulary", one of the students said in the interview. Another student emphasized the importance of targeted translation skills practices. "Translating about 30 sentences of the similar structure strengthens my memory of a certain translation skill. Practice really makes perfect", another student said while giving feedback.

Observer's comment. English-Chinese: The main practice of this unit includes after-class exercises, in-class teacher's comment on the exercises, typical sentence structure analysis, and targeted translation skills practice. Some people may consider the exercises out of date while I personally think they are necessary for a good foundation in translation training. Two teaching methods impress me most. The first one is "targeted translation skills practices" (teaching step 3). Each targeted exercise (usually contains 30-40 sentences) focuses on one translation skill such as non-attributive clauses, appositive clauses, long sentences, voice conversion, or word addition. The exercise effectively reinforces students' good command of difficult sentences' translation in homework assignments. The second method is teaching students how to use the BNC (British National Corpus, http://www.natcorp.ox.ac.uk/) to search for a word or a phrase. This service is particularly useful for those who want to see whether a word occurs in the BNC, compare different variants to see which is more frequent and so on. This method can help students judge which word or phrase is more idiomatic.

Generally speaking, the difficult point in English-Chinese translation is the comprehension of some key words, idioms, and cultural background in an English source text. Without it the translation is unacceptable no matter how fluent it is (YANG, 2002). Correct comprehension also relies on the accurate choice of Chinese expressions. Hence improving Chinese language proficiency is equally vital to enhance the quality of English-Chinese translation.

Teaching steps of Chinese-English translation. (1) Each student translated a practice text of about 600 words from Chinese into English and brought it to the next class;

(2) In class each student was asked to translate a sentence of the practice text, during which other students were encouraged to speak out their different translations. To each translated sentence a student put forward, the teacher would clarify why or why not a certain word or an expression in the sentence was appropriate in that context;

(3) Students were required to shape up notes of the translation practice text in step 1 and submit them on LMS by each Saturday;

(4) The teacher delivered handouts of the answer for students' reference with footnotes to explicitly explain why a particular word was chosen or an expression was used in a certain context;

(5) Time permitting, students would be asked to do more translation exercises in class with the assistance of dictionaries and hand in after class. The teacher usually corrected wrong expressions, underlined mistakes or put a tick at the end of a well-translated sentence. The corrected exercises would be returned to students the next class.

Students' feedback (Unit 4). Chinese-English: According to students' feedback in the questionnaire, the common difficult problems included idiomatic expressions of English language and the usage of proper sentence structure. The three students were aware of the importance of cultivating English language sense. They also recognized the teaching step in which students raised other alternatives and the teacher then clarified them. For example, "I like to confirm with the teacher as soon as I can on the similar English expressions that confused me, which is the most direct way to minimize my Chinglish". Students suggested that more translation exercises and systematic training were needed in different fields such as finance, politics, culture, etc. 
Table 4 indicates students' general feedback on Unit 4 . This unit got the highest total score (154) among the four units, which means students tended to believe that more practice and more detailed feedback by teachers are the best way to improve translation competence and achieve learning outcome.

Table 4

Students' Feedback on Unit 4

\begin{tabular}{lllll}
\hline Statement & St1 & St2 & St3 & Subtotal \\
\hline S1/S8: This unit can/cannot effectively improve my translation competence. & $6 / 7$ & $6 / 7$ & $7 / 7$ & 40 \\
S2/S9: This unit can/cannot effectively improve my ability of reading, writing, & $6 / 6$ & $6 / 7$ & $6 / 6$ & 37 \\
listening, and speaking. & & & & 38 \\
S3/S10: This unit can/cannot help to achieve the goal of cultivating Master of & $6 / 6$ & $6 / 6$ & $7 / 7$ & 38 \\
Translation. & & & 39 \\
S4/S11: This unit can/cannot foster teaching contents and develop the ability of & $6 / 6$ & $7 / 7$ & $6 / 7$ & 39 \\
independent and critical thinking. & & & & 154 \\
\hline Total
\end{tabular}

Observer's comment. Chinese-English: Associate Professor Andrew Endrey is the other lecturer of this unit. $\mathrm{He}$ is a graduate of the University of Melbourne and has been a Chinese Interpreter and Senior Translator for various organizations. This part of teaching was the one I was most interested in because my students were back in China and I were eager to learn the ways to avoid Chinglish (Chinese English) in Chinese-English translation. Although the teaching methods were similar to the above English-Chinese teaching, one of the teacher's distinctive teaching methods was teacher-students interaction. After one student read his/her translated sentence, the teacher corrected some errors and explained why he used that particular way. Other students actively put forward to their own translations and the teacher would clearly explain which and why was/was not acceptable in English language. In this way, students learned quickly the idiomatic ways of expression. The other distinctive teaching method was the repetition of some key words' translation in four different forms. Each form described respectively in Chinese-English teaching steps 1 to 4 strengthening students' memory of the difficult points and their corresponding translation skills in the exercise. Of course the above mentioned was by no means the only way for students to improve their translation competence. I consulted Mr. Endrey in terms of this question and his reply was that improving translation competence required lots of practice of various forms. In addition to this, reading a variety of textual genres and keeping a journal were also essential preconditions. Keeping a journal using new words and expressions one had learned while reading allowed him/her to practice higher quality translating. Gradually, an increasing number of idiomatic expressions would be internalized. That was the reason each of the four units involved much reading, writing, speaking, and listening, which combined to make contributions to better students' translation competence.

In short, Tomlinson's (1998) 3-p model, namely presentation, practice, and production, is essential for translator training. The 3-p represents three steps in translation teaching and they are embodied in Unit 4's teaching. According to Ms. Ji and Mr. Endrey, specific Chinese-English and English-Chinese translation techniques had been presented in the first semester. The tasks of the second semester were to use and solidify relevant techniques students had learned. Translation homework was assigned to students as further productions after in-class practice. As both English-Chinese and Chinese-English translation competence depends on the ability to manipulate the two languages, "there is need to lay a firm foundation of bilingual competence before 
and while receiving training in Translation. When well planned language teaching can help translation students improve their bilingual skills and in turn overall translation competence and performance" (LI, 2001, p. 1). Fawcett's (1997) states that, without grounding in linguistics, the translator is like "somebody who is working with an incomplete toolkit" (p. viii).

\section{Research Questions to Be Answered}

\section{What Are the Popular Teaching Methods for Students of Master of Translation Studies in the UWA to} Achieve the Learning Outcomes?

The four units (Interdisciplinary Translation, Culture and Media, Translation Localization, General/Specialized Translation) adopt the following models respectively:

(1) Lecture/Tutorial;

(2) Interaction-Reflection-Internalization in tutorials;

(3) Lectures in computer laboratory—-Teacher's demonstration —-Students' hands-on practice;

(4) Interaction-Practice-Clarification.

According to Delisele (1980), translation teaching "should be driven by clear objectives" (quoted in LI, 2013, p. 6). Teaching methods "should be shifted from the teacher and teaching to students and learning" (Nord, 1991; Gonzalez-Davis \& Scott-Tennent, 2005, ibid.). "Activities should be designed to facilitate learning (Gonzalez-Davies, 2003; Hurtado Albir, 1999), whether they are tasks previously performed by the teachers (Vienne, 1994), simulated translation tasks (Gouadec, 2004), or authentic translation projects (Kiraly, 2005; Li, 2000; Lee-jahnke, 2011)" (ibid.). The key points quoted in the above are all embodied in the translation teaching of Master of Translation Studies in the UWA-They are objective-oriented, learner-centered and task-based. Task-based teaching method is more effective for students learning English as a second language (Candlin, 1987) and Willis (1996) proposes that a cycle of task-based teaching should consist of six stages, namely, pre-task, task cycle (Task, Planning, Report), and language focus (Analysis, Practice). In translation teaching context, LI De-feng (2013) suggests that the task-based model should consist of the following six stages: pre-task, reporting, analysis, revision and reflection. Translation teaching methods in the UWA are almost in line with the six stages the two researchers put forward respectively, which meet students' needs to a considerable extent. In addition to this, all the units during the two-year study are approved by the NAATI (the National Accreditation Authority for Translators and Interpreters of Australia). That is to say if a student can get a 70\% mark in the translation units, he/she will be granted accredited by NAATI as a professional translator in Australia or other countries that recognize NAATI accreditation.

\section{What Are the Implications for How to Minimize Chinglish in Chinese-English Translation?}

There is not a simple way to minimize Chinglish in Chinese-English translation. Having a good command of both English and Chinese language is the foundation, which is followed by the combination of plenty of practices in reading, writing, listening, speaking, and translating. Implications during the translation class observation are as follows:

To minimize Chinglish in Chinese-English translation, first of all, college English teachers must improve their own Chinese-English translation competence. This is one of the most vital implications I gained from the fact that all the lecturers in the four units of Master of Translation Studies are professional translators or 
interpreters with rich practical experience. It is not realistic to imagine that College English teachers who have low levels of translation competence will be able to help improve students' translation competence. Teachers themselves are supposed to be more sensitive to Chinglish or to teach students how to search for evidence to prove an expression is more idiomatic. Foreign language educational policy makers also need to realize that any examination or teaching reform aiming to improve learners' any language application ability but ignoring the situation of teachers is to put the cart before the horse and is thus unlikely to succeed. Consequently, in-service teacher training and continuous improvement on English Language proficiency are essential for College English teachers, who should take the most responsibility for it.

Secondly, from a macro perspective, students should develop a strict and earnest attitude towards translation study by realizing the purpose of translation study is not just for passing examinations but for better effective communication. When encountering uncertain translation problems, one should try his/her best to search for sufficient evidence to find a solution rather than just making do with some unchecked translation that may not be accurate. In this process, students' ability of independent and critical thinking, reflection and summary will be internalized. Gradually, the ability to identify and eliminate Chinglish will be improved.

Thirdly, from a learning strategy standpoint, teachers and students should: (1) Enhance the competence in both Chinese and English languages. One of the five sub-competences in PACTE translation competence model (PACTE Group, 2005, p. 610) is bilingual sub-competence, which is made up of pragmatic, socio-linguistic, textual and lexical-grammatical knowledge in each language. That is to say, in Chinese-English translation context, translation competence mainly depends on three factors, namely Chinese language competence, English language competence, and the ability to transfer between the two languages. Hence, extensive reading of both Chinese and English languages will significantly help improve the competence to transfer between the two languages. This will eventually contribute to improve the accuracy of Chinese-English translation; (2) Cultivate "Tools and Research Competence" (Göpferich, 2009), which corresponds to the PACTE Groups's "Instrumental Sub-competence (PACTE Group, 2005, p. 610). Göpferich thinks this competence

Comprises the ability to use translation-specific conventional and electronic tools, from reference works such as dictionaries and encyclopedias (either printed or electronic), term banks and other databases, parallel texts, the use of engines and corpora to the use of word processors, terminology and translation management systems as well as machine translation systems. (PACTE Group, 2005, p. 610)

According to the questionnaire, the translation strategies most frequently used by the three students are Google, electronic dictionaries, printed dictionaries, and parallel texts. Even though using Chinese-English electronic dictionaries sometimes are the best and quickest way to solve translation problems, it is more vital to develop the habit of using English-English dictionaries to assist translation. Chinese-English dictionary sometimes gives an equivalent English word that may not convey the idea in a particular context. Hence, the best way to ensure the meaning and the usage of a word is to consult English-English dictionaries. In this way students can check the alignment of the usage of the word in the dictionary and in the source text. Apart from various dictionaries, reading parallel texts before translating is also critical to produce high-quality translation. Parallel texts written by English native speakers can, to a certain degree, provide professional or idiomatic ways of expressions in a certain field. This is an effective way to avoid Chinglish. 
The last but not least, useful translation strategy the three students did not mentioned in the questionnaire is corpus, such as BNC corpus or other software/website giving collocation and word ratios. Mastering the tools mentioned above is the basic skill to help guarantee translation quality.

It is nothing unusual that Chinglish is found in Chinese students' or even teachers' Chinese-English translations. It is difficult for any person to do well in translating Chinese to English before his/her English language proficiency is perfect. In fact, students whose first language is English and second language is Chinese often suffer from a similar problem of translating or interpreting from English to Chinese. The only way to compensate the lack of English or Chinese language proficiency is to consult a large quantity of related materials and to be familiar with the correct usage and expressions of uncertain English words. This is what a student or a teacher eager to improve his/her Chinese-English translation competence should be able to do.

\section{What Translation Teaching Methods of the UWA Can Be Adopted in Chinese College English Classroom to Better Develop Students' Translation Competene?}

Given the considerable differences between teaching translation to non-English majors and professional translators, adjustments will have to be made to non-English majors' translation teaching methods. A Chinese College English teacher is required to teach one theme-based unit of the integrated English course (including teaching the skills of reading, writing, listening, speaking, and translating) in 4-5 class periods (about 200 to 250 minutes). Considering the fact that non-English majors are not trained to be professional translators and the limited class periods, translation theories can be omitted. As the five skills are interactive, a large amount of comprehensible input via reading and listening will benefit writing, speaking, and translating eventually. While teaching translation in College English class, a teacher can use the methods of Interaction-Reflection-Internalization and Interaction-Practice-Clarification. For the former, students should be required to do assigned reading and writing relating to culture, economy, politics, and society. The latter can be used to train and strengthen targeted translation skills via corresponding exercises. The proverb of "Practice makes perfect" is always true in translation studies.

\section{Conclusion}

Master of Translation Studies of the UWA is all about reading, writing, listening, speaking, translating, and critical thinking. It is a real integrated course of developing these five competences of English language. If both Chinese College English teachers and non-English-majored students have the motivation to improve their Chinese-English translation competence to a higher level, the UWA teaching methods mentioned above are worthy of their consideration. However, the prerequisite is that both parties must invest in sufficient time and sustained effort. Unfortunately, there is no shortcut if one aspires to become a good and well respected translator.

\section{References}

Candlin, C. N. (1987). Towards task-based learning. In C. Candlin and D. Murphy (Eds.), Lancaster practical papers in English language education: Language learning tasks (Vol. 7, pp. 5-22). Englewood Cliffs, NJ: Prentice Hall.

Crookall, D., \& Oxford, R. L. (1990). Linking language learning and simulation/gaming. In D. Crookall and R. L. Oxford (Eds.), Simulation, gaming, and language learning (pp. 3-24), New York: Newbury House.

Fawcett, P. (1997). Translation and language. Manchester: St Jerome.

Gile, D. (2004). Integrated problem and decision reporting as a translator training tool. The Journal of Specialised Translation, 2 , 2-20. Retrieved from http://www.jostrans.org 
Göpferich, S. (2009). Towards a model of translation competence and its acquisition: The longitudinal study. In S. Göpferich, A. L. Jakobsen, and I. M. Mees (Eds.), Behind the mind: Methods, models and results in translation process research (pp. 11-37). Copenhagen: Samfundslitteratur.

Hansen, G. (2006). Retrospection methods in translator training and translation research. The Journal of Specialized Translation, 5 , 2-41

LI, C. S. (2006). Ensuring adepquate results with the "Due Process": The role of translator's notes in translation teaching. Chinese Translation Journal, 27(3), 49-52.

LI, D. (2001). Language teaching in translator training. Babel, 47(3), 342-353.

LI, D. F. (2013). Teaching business translation. The Interpreter and Translator Trainer, 7(1), 1-26.

LIU, H. P. (2011). The development of translation competence in different stages and its pedagogical research. Chinese Translators Journal, 1, 37-45.

LIU, H. P. (2013). Translation teaching models: Theory and application. Chinese Translators Journal, 2, 50-55.

PACTE Group. (2005). Investigating translation competence: Conceptual and methodo-logical issues. Meta, 50(2), 609-618.

Tomlinson, B. (Ed.). (1998). Materials development in language teaching. Cambridge: Cambridge University Press.

Willis, J. (1996). A framework for task-based learning. Harlow, UK: Longman.

YANG, S. Z. (2002). How to improve junior English-majored students' English-Chinese translation competence. Chinese Translators Journal, 23(6), 55-56.

\section{Appendix: Questionnaire}

\section{Session 1:}

Directions: Read each statement on the following page. Please respond to the statements as they apply to your translation studies. Decide whether you (1) Strongly Disagree, (2) Moderately Disagree, (3) Slightly Disagree, (4) Neutral, (5) Slightly Agree,

(6) Moderately Agree, (7) Strongly Agree.

1. This unit can effectively improve my translation competence.

( ) Unit 1: Interdisciplinary Translation studies

( ) Unit 2: Advanced Language Skill/Culture and Media

( ) Unit 3: Translation Localization

( ) Unit 4: General Translation/ Specialized Translation

2. This unit can effectively improve my ability of reading, writing, listening and speaking.

Unit 1: ( ) Unit 2: ( ) Unit 3: ( ) Unit 4: ( )

3. This unit can help to achieve the goal of cultivating Master of Translation.

Unit 1: ( ) Unit 2: ( ) Unit 3: ( ) Unit 4: ( )

4: This unit can foster teaching contents and develop the ability of independent and critical thinking.

Unit 1: ( ) Unit 2: ( ) Unit 3: ( ) Unit 4: ( )

5. This unit has too much homework. I hope they can be reduced.

Unit 1: ( ) Unit 2: ( ) Unit 3: ( ) Unit 4: ( )

6. This unit has less homework. I hope they can be increased.

Unit 1: ( ) Unit 2: ( ) Unit 3: ( ) Unit 4: ( )

7. This unit has moderate homework.

Unit 1: ( ) Unit 2: ( ) Unit 3: ( ) Unit 4: ( )

8. This unit cannot effectively improve my translation competence.

Unit 1: ( ) Unit 2: ( ) Unit 3: ( ) Unit 4: ( )

9. This unit cannot effectively improve my ability of reading, writing, listening and speaking.

Unit 1: ( ) Unit 2: ( ) Unit 3: ( ) Unit 4: ( ) 
10. This unit cannot help to achieve the goal of cultivating Master of Translation.

Unit 1: ( ) Unit 2: ( ) Unit 3: ( ) Unit 4: ( )

11. This unit cannot foster teaching contents and develop the ability of independent and critical thinking.

Unit 1: ( ) Unit 2: ( ) Unit 3: ( ) Unit 4: ( )

\section{Session 2:}

Short-answer questions:

1. What do you think is the most difficult part in Unit 4 (General Translation)?

English-Chinese/Chinese-English

Most difficult part:

Strategies to get over it:

What help do you want from your teacher:

2. Briefly summarize

What have you learned in each unit?

What teaching methods do you like in each unit?

What suggestions do you have for each unit? 